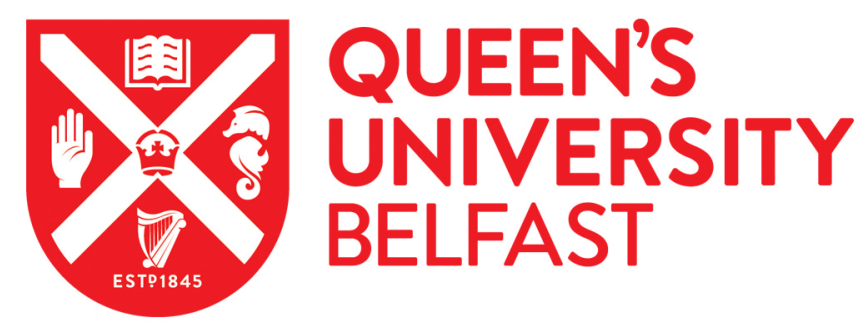

\title{
A comparison of HFrEF vs HFpEF's clinical workload and cost in the first year following hospitalization and enrollment in a disease management program.
}

Murphy, T. M., Waterhouse, D. F., James, S., Casey, C., Fitzgerald, E., O'Connell, E., Watson, C., Gallagher, J., Ledwidge, M., \& McDonald, K. (2016). A comparison of HFrEF vs HFpEF's clinical workload and cost in the first year following hospitalization and enrollment in a disease management program. International Journal of Cardiology. https://doi.org/10.1016/j.ijcard.2016.12.057

\section{Published in:}

International Journal of Cardiology

\section{Document Version:}

Peer reviewed version

Queen's University Belfast - Research Portal:

Link to publication record in Queen's University Belfast Research Portal

\author{
Publisher rights \\ (C) 2017 Elsevier Ireland Ltd. All rights reserved.. This manuscript version is made available under the CC-BY-NC-ND 4.0 license \\ http://creativecommons.org/licenses/by-nc-nd/4.0/ which permits distribution and reproduction for non-commercial purposes, provided the \\ author and source are cited.
}

\section{General rights}

Copyright for the publications made accessible via the Queen's University Belfast Research Portal is retained by the author(s) and / or other copyright owners and it is a condition of accessing these publications that users recognise and abide by the legal requirements associated with these rights.

Take down policy

The Research Portal is Queen's institutional repository that provides access to Queen's research output. Every effort has been made to ensure that content in the Research Portal does not infringe any person's rights, or applicable UK laws. If you discover content in the Research Portal that you believe breaches copyright or violates any law, please contact openaccess@qub.ac.uk. 
Title Page -

Full Title - A comparison of HFrEF vs HFpEF's clinical workload and cost in the first year following hospitalization and enrollment in a disease management program

Murphy TM, MD - St Vincents University Hospital, Dublin

Waterhouse DF, MD - St Vincents University Hospital, Dublin

James S, MD - St Vincents University Hospital, Dublin

Casey C, MD - St Vincents University Hospital, Dublin

Fitzgerald E, MD - St Vincents University Hospital, Dublin

O’Connell E, BA -St Vincents University Hospital, Dublin

Watson C, PhD - St Vincents University Hospital, Dublin, \& Centre for Experimental Medicine,

Queen's University Belfast, Northern Ireland

Gallagher J, MD- St Vincents University Hospital, Dublin

Ledwidge M, PhD - St Vincents University Hospital, Dublin

McDonald K. MD - St Vincents University Hospital, Dublin

All authors have nothing to disclose.

From ; Heart Failure Unit

St Vincent's University Hospital

Dublin 4

Ireland

Correspondence to Prof. Ken McDonald - kenneth.mcdonald@ucd.ie

Telephone 00353 (1) 2004000

Department of Cardiology

St Vincents University Hospital

Elm park, Dublin 4

Ireland

Total Word Count - 4177 
A comparison of HFrEF vs HFpEF's clinical workload and cost in the first year

following hospitalization and enrollment in a disease management program

Murphy TM, Waterhouse DF, James S, Casey Q, Fitzgerald E, O'Connell E, Watson C, Gallagher J, Ledwidge M, McDonald K.

\section{Background}

Admission with heart failure (HF) is a milestone in the progression of the disease, often resulting in higher intensity medical care and ensuing readmissions. Whilst there is evidence supporting enrolling patients in a heart failure disease management program (HF-DMP), not all reported HF-DMPs have systematically enrolled patients with HF with preserved ejection fraction (HFpEF) and there is a scarcity of literature differentiating costs based on HFphenotype.

Methods

1292 consenting, consecutive patients admitted with a primary diagnosis of HF were enrolled in a hospital based HF-DMP and categorized as $\mathrm{HFpEF}(\mathrm{EF} \geq 45 \%)$ or $\mathrm{HFrEF}(\mathrm{EF}<45 \%)$.

Hospitalizations, primary care, medications, and DMP workload with associated costs were evaluated assessing DMP clinic-visits, telephonic contact, medication changes over 1 year using a mixture of casemix and micro-costing techniques.

Results

The total average annual cost per patient was marginally higher in patients with HFrEF $€ 13,011(12011,14078)$ than HFpEF, €12206(11009,13518). However, emergency noncardiovascular admission rates and average cost per patient were higher in the HFpEF vs HFrEF group(0.46 vs 0.31 per patient/12 months) \& €655(318,1073) vs €584(396,812). In the first 3 months of the outpatient HF-DMP the HFrEF population cost more on average $€ 791(764,819)$ vs €693(660,728).

Conclusion 
There are greater short-term (3-month) costs of HFrEF versus HFpEF as part of a HF-DMP following an admission. However, long-term (3-12month) costs of HFpEF are greater because of higher non-cardiovascular rehospitalisations. As HFpEF becomes the dominant form of HF, more work is required in HF-DMPs to address prevention of non-cardiovascular rehospitalisations and to integrate hospital based HF-DMPs into primary healthcare structures.

\section{Introduction:}

Heart failure (HF) affects over 5 million individuals in the USA with direct and indirect costs of more than $\$ 30$ billion per annum, with costs expected to rise almost $120 \%$ to $\$ 72$ billion in 2030. ${ }^{12}$ A significant portion of this expenditure is related to frequent hospitalizations with a reported 1-month readmission rate of $25 \%$ and 1 year readmission rate of $43.9 \%$ following an admission with HF. 345 In order to address the high readmission rates and associated burgeoning financial costs, HF disease management programs (HF-DMPs) were developed to improve patient outcomes, reduce mortality and re-admission rates in HF patients.

Whilst there is evidence to support the benefits of HF-DMPs, little data exists to assist clinicians and policy makers identify and cost the resources that are needed to implement the steps to provide optimal care. 67891011 In addition, the majority of literature regarding HFDMPs fails to differentiate the study populations or outcomes based on heart failure phenotype, despite distinct differences in the underlying pathology and management. ${ }^{1213}$ Furthermore, several randomized controlled trials reviewing HF-DMPs omit patients with preserved ejection fraction HF. ${ }^{14} 1516$ Subsequently, the clinical and fiscal load of each individual cohort is poorly defined and requires further clarification to guide appropriate allocation of resources. 
Therefore, the purpose of this report is to investigate resource utilisation and cost comparing heart failure with reduced ejection fraction (HFrEF) and heart failure with preserved ejection fraction HFpEF during the first year following hospitalization with HF managed within a DMP.

\section{Methods:}

This is a retrospective analysis of 1292 patients followed for 1 year after admission with HF. Consenting, consecutive patients admitted with a primary diagnosis of HF were enrolled in a hospital based, HF-DMP and were categorized as HFpEF and HFrEF. (See Appendix for Structure of DMP) The average cost-per-case for inpatient and outpatient visit was calculated from the National Casemix Program, which classifies DRGs (diagnosis-related groups) based on the primary ICD-10 code assigned to the case, telephone contact was calculated by microcosting and all costs were discounted to the same year of analysis $2013 .{ }^{17}$

\section{Analysis of Clinical Workload :}

The clinical workload was assessed based on five parameters:

Admissions:

Admissions to hospital were classified due to cause, including emergency hospitalization for $\mathrm{HF}$, non-HF cardiovascular reasons and non-cardiovascular emergency as well as elective admissions. End point information was obtained from patient interview with direct entering onto the data base. Information was cross checked against patient medical records and the 
admission-discharge records of the three local hospitals that provide emergency services. Mortality rates were also calculated.

Clinic visits:

Clinic visits were assessed as total number and subdivided into scheduled, including visits for drug titration, and unscheduled clinic visits defined as physician reviews of the patient as result of patient/family physician reported event.

Phone contact:

Total telephonic contact between the HF unit and patient and their primary carer was noted and subdivided into outbound calls (initiated from the HF unit and driven almost exclusively by protocol calls) and inbound calls (initiated by the patient and reflecting concern over potential clinical deterioration)

Medication Titrations:

Information on titration of medication was calculated from prescription notes.

Family Physician Visits:

Clinic visits were assessed as total number throughout the course of a year.

The above metrics were subdivided into HFrEF and HFpEF. HFrEF was defined as those with left ventricular ejection fraction $<45 \%$ at initial presentation, whilst those with an ejection fraction > or equal to $45 \%$ were classified as HFpEF. Hospital costs were calculated using average casemix data weighted for type and severity of admission multiplied by the actual length of stay. DMP costs were calculated using a mixture of casemix and microcosting 
techniques. For example, we took national casemix figures for HF-DMP clinic attendances applied to the number of scheduled and unscheduled visits and we used microcosting techniques to determine resource utilization of outbound and inbound telemonitoring. All costs were taken from the provider perspective and discounted using $5 \%$ rate to the year of analysis.

\section{Statistical Analysis}

Summary data for continuous variables are presented in the form 50th percentile [25th percentile:75th percentile] - median [interquartile range] - unless otherwise indicated. Categorical variables are presented as absolute numbers and percentages. Where $p$-values are reported, they refer to t-tests (for normally distributed data), wilcoxon tests (for continuous non-normally distributed data) and chi-square tests (for categorical data ). Where multiple tests are performed on a single outcome variable, $p$-values have been adjusted using the Bonferroni method of correction. All tests are two-tailed unless otherwise indicated and the threshold for statistical significance is taken as 0.05. R Foundation for Statistical Computing, Vienna, Austria; ISBN 3-900051-07-0, (http://www.R-project.org) was used for all calculations.

\section{Results}

\section{Population Demographics (Table 1)}

We report on 1292 survivors of hospitalization with HF managed within a DMP. The mean age of the cohort is 74.5 years, with a marginal dominance of male patients. The Charlson comorbidity index was high reflecting advanced age and a high comorbidity burden. The dominant HF etiology was ischemic. All patients were NYHA Class IV on admission, with markedly elevated natriuretic peptide levels, which while still elevated at discharge, showed a significant decline consistent with clinical stabilization.

Sixty eight percent of the population was defined as HFrEF on admission. This cohort were younger and more male-dominated that the HFpEF cohort. The HFpEF cohort had a higher 
Charlson index and hypertension was a more prevalent etiology. Atrial fibrillation was more commonly observed in the HFpEF cohort. B-type natriuretic peptide (BNP) was less elevated in HFpEF patients on admission but, as with the HFrEF group, declined significantly by the time of discharge. The median length of stay in the entire cohort was 9 days with a statistically significant shorter hospitalization period for those with HFpEF.

\section{Clinical Workload Indices:}

Clinic Visits

Over the three-month program duration there were 5046 clinical visits, with a mean of 3.9 visits/patient. Total clinical visit time/patient was 132 [99:171] mins. Overall there were 4442 scheduled visits and 604 unscheduled visits, with a rate of 0.47 unscheduled visits/patient. Notably, almost $30 \%$ of the total cohort required at least one unscheduled visit, with the most frequent use of this service in the first week post discharge (Figure 1). Overall, 19.2\% of patients had 1 unscheduled visit, while $10.8 \%$ of patients had $>1$ unscheduled visits during this three month period.

There were a greater number of total visits among those with HFrEF when compared with the HFpEF cohort. Those with HFrEF had 4.0 visits/patient while those with HFpEF had 3.7 visits/patient $($ rate ratio $(95 \% \mathrm{Cl})=1.08(1.02,1.15) ; \mathrm{p}=0.01)$. This difference reflects an increased number of scheduled visits in the HFrEF group (3.5 vs. 3.2 per patient), likely secondary to the increased number of medication changes in this group reflecting titration of disease management drugs. Consistent with this observation was the observation that total clinic time was greater in those with HFrEF compared with patients with HFpEF (135 vs. 125 mins, Wilcoxon $\mathrm{p}=0.03)$.

When unscheduled visits are assessed, HFpEF had a similar frequency of unscheduled attendance to HFrEF (HFpEF 0.49 vs. HFrEF 0.46, Rate ratio $p=0.46$ ). Within the HFpEF cohort, $22.5 \%$ of patients had 1 unscheduled visit and $10.7 \%$ had $>1$ unscheduled visits. The 
HFrEF cohort had slightly less with $17.6 \%$ of this group having 1 unscheduled visit and $10.8 \%$ having $>1$ unscheduled visits.

Phone Calls ( Supp. Figure 2)

There were non-significant differences in frequency of inbound and outbound telemonitoring phone calls in those with HFrEF vs. those with HFpEF (inbound, HFrEF 16.9 calls/ 100 patients / week, HFpEF had 16.1 calls/ 100 patients / week; outbound HFrEF 84.9 calls/ 100 patients/ week, HFpEF 81.9 calls/ 100 patients / week).

Medication Changes (Supp. Table 1)

i Diuretics

Ninty-two per cent of patients were prescribed diuretics with a mean dose at discharge from hospital of $58.7 \mathrm{mg}$ frusemide equivalent. Mean dose of diuretic at the end of the three-month program was $63.1 \mathrm{mg}$ frusemide eq. Overall, $55.3 \%$ of patients did not have their dose altered during the three-month program, while $22.5 \%$ had their first diuretic dose alteration within one month of discharge, $11.1 \%$ within $1-2$ months and $11.1 \%$ after 2 months. Overall, alteration of diuretic dose (at least one increase or decrease) occurred in $44.7 \%$ of patients with $25.8 \%$ having one dose change and $18.9 \%$ having $>1$ dose changes during the three-moth program duration.

There was no significant difference in diuretic discharge dose between those with HFrEF vs. HFpEF (HFrEF: $58.4 \mathrm{mg}, \mathrm{HFpEF}: 59.3 \mathrm{mg}, \mathrm{p}>.05)$. At the completion of the three-month program, the dose of diuretic was similar between HFrEF and HFpEF. (HFrEF: $61.7 \mathrm{mg}$, HFpEF: $66.2 \mathrm{mg} ; \mathrm{p}>.05$ ) and those with HFpEF had as frequent alterations in diuretic dose when compared to those with HFrEF (HFrEF 0.71 vs HFpEF 0.77 per patient; $p>05$ ).

ii $A C E i / A R B$ 
At discharge $73.7 \%$ of the patients were prescribed ACEi with at least one dose alteration in ACEI occurring in $31.9 \%$ of the population during the three months of the program, with a total of 621 dose adjustments. A total of 494 patients did not have their dose changed following in the first 3 months following discharge, 131 (18.0\%) had a dosage alteration within a month, 70 (9.6\%) within 1-2 months and $33(4.5 \%)$ within 2-3 months. 93 patients (9.4\%) were on ARBs at discharge. 71 of those (76.3\%) did not have their dose altered within 3 months of discharge, 15 (16.1\%) had a dosage alteration within a month, 1 (1.1\%) within 1-2 months and 6 (6.5\%) within 2-3 months.

As anticipated, dose changes in ACEi/ARB were less common in the HFpEF group but still occurred in approximately $20 \%$ of those on an ACEi. When compared to patients with HFpEF, patients with HFrEF had, as anticipated, a higher rate of prescription of ACEi, at higher doses, reflecting more frequent dose titrations, than those with HFpEF.

\section{iii Beta Blockers}

Six hundred and sixty-nine patients (67.7\%) were on beta blockers at discharge. 383 of these (57.2\%) did not have their dose altered within 3 months of discharge, $141(21.1 \%)$ had a dosage alteration within a month, $85(12.7 \%)$ within 1-2 months and 60 (9.0\%) within 2-3 months.

Again, dose changes in beta-blockers were less common in the HFpEF group, but still occurred in one third of this population. Patients with HFrEF were more frequently prescribed beta blockers, at higher doses than those with HFpEF.

iv Aldosterone Antagonists

Eighty-seven patients (8.8\%) were prescribed an aldosterone antagonist on discharge. At three month follow up, 141 (12.4\%) were prescribed an aldosterone antagonist. Mean dose of an aldosterone antagonist at three months was $24.1 \mathrm{mg}$. When compared, there was a significant difference in frequency of prescription an aldosterone antagonist between those with HFrEF vs. HFpEF (HFrEF 24.7\%; HFpEF 9.7\%; $p$ 0.001) as well as a difference in 
dose of an aldosterone antagonist between the groups (HFrEF 24.04mg; HFpEF 27.8mg; $p<0.01)$

Readmission and Mortality Event Rate (Table 2)

Overall the readmission rates in HFpEF were higher than HFrEF over the 12 months follow up (0.99 vs 0.858 per patient). The ADHF and emergency cardiovascular readmission rates over 12 months follow up were similar for HFpEF as HFrEF ( 0.31 vs. 0.28 per patient), as were mortality rates ( 0.12 vs. 0.13 per patient). However, emergency non-cardiovascular admission rates were notably higher in the HFpEF vs HFrEF group ( 0.46 vs 0.31 per patient over 12 months).

\section{Cost Analysis (Table 3, Figure 2)}

The total average cost per patient was higher in patients with HFrEF €13,011 $(12011,14078)$ than HFpEF, $€ 12206(11009,13518)$ with a significant proportion of the total cost attributed to the index admission.

Readmission cost per patient with HFpEF was an average of $€ 5396(4390,6494)$ versus $€ 4287(3574,5042)$ for HFrEF. This is explained by higher average cost per patient for readmission for non-cardiovascular emergencies among patients with HFpEF than HFrEF.

The average cost per patient, attributed to the clinical workload of the HF-DMP, was greater in patients with HFrEF than HFpEF, costing €8.78 per day versus $€ 7.70$ during a 90 day intensive DMP and €2.74 versus €2.16 per day for the remaining 9 months. The majority of this cost was due to scheduled and titration visits.

The annual clinical workload cost of a HF-DMP was approximately $11 \%$ of the total annual average cost per HF patient, with the majority of the total expenditure allocated to hospitalizations, mainly the index admission and subsequent readmissions. 


\section{Discussion:}

Multiple studies have demonstrated that disease management programs significantly reduce mortality and re-hospitalizations amongst patients with HF.18 192021 However, not all reported HF-DMPs routinely include HFpEF patients and few data exist to assist clinicians and policy makers identify the resources that are needed to implement the steps to provide this form of care. In addition, there is a dearth of data comparing workload intensity between HFpEF \& HFrEF specifically, an important issue given the increasing number of HFpEF patients admitted to hospital with acute decompensated heart failure and at risk for further events. ${ }^{22} 23$ Responding to these deficiencies in the literature, this paper presents detailed information on the clinical and financial landscape of HF and associated outcomes of patients managed within a structured cardiology led disease management program.

Assessment of workload comprised analysis of three metrics of patient interaction reflective of scheduled and unscheduled activity. Clinic volume, as anticipated, was dominated by scheduled visits as mandated by the programmatic follow up post discharge. However, there was an evident need to provide immediate same day review for features suggestive of emerging clinical deterioration, with $30 \%$ of the population requiring same-day review within the first three months post discharge. Approximately $10 \%$ required this service on more than one occasion and the most frequent use was in the first week post discharge. It is also noteworthy that this unscheduled service was required equally for those with HFpEF and HFrEF. It is likely that this service was central in achieving a low rate of readmission, and is consistent with a previous observation from our unit that demonstrated that in $72 \%$ of such presentations rehospitalization could be prevented. ${ }^{24}$

A similar observation was made in regard to telephone contact between the patient and the HF unit. The majority of calls were protocol-driven outbound calls but there was a steady weekly use of the inbound call facility of approximately $15 \%$ of call volume throughout the 
duration of the program. This again reflecting the need to provide immediate response to the patient, family or general practitioner on matters related to the clinical stability.

Drug dose alteration was also a major contributor to workload within the initial months post discharge. As anticipated, adjustment in ACEi/ARB and Beta-Blocker therapy was more common in the HFrEF cohort. However, the single most frequent dose alteration occurred in the diuretic dose and was required as often in the HFpEF population as in the HFrEF group, underlying the equivalence in clinical instability in the two cohorts.

Cost analysis, based on the in-depth assessment of workload and readmission figures using a mixture of casemix and microcosting approaches, demonstrated a marginal increase in cost in the care of the HFrEF patient over a period of one year including the index admission. This is explained by the longer length of stay of the index admission and the higher scheduled clinic volume in this population. It is noteworthy however, that the HFpEF population accumulated a greater number of emergency non-cardiovascular admissions. This would be expected from this population which was older and more frail than the HFrEF cohort and consistent with other data sets. ${ }^{25}$

The HF-DMP is designed to help transition patients through the "at risk" stage post hospital discharge and facilitate continued close clinical observation, ongoing education on self care and titration of medication with an aim of reducing hospital readmission and improving long term outcome. Increasing focus on the importance of readmissions has developed as a result of the penalty system for readmission within 30 days of discharge in the United States. The data presented herein, underline the relative low cost of an intensive DMP compared to the costs of admission that the service is designed to prevent.

In transiting patients to a zone of relative clinical stability post discharge this data also underlines the need to enroll patients with HFpEF into the DMP. Thorough analysis of unscheduled clinic visit frequency, use of inbound phone calls and importantly the equal need to adjust diuretics in this cohort suggests that this population pose as great a HF challenge as 
patients with HFrEF. However, the data also demonstrate an increased susceptibility of the HFpEF patient to non-CV emergency admission and points towards a need for a DMP to consider close clinical interaction with other medical specialties and indeed social and community services.

In interpreting these data several issues need to be taken into consideration. It is important to note that the data presented here are observational and from a single centre within one healthcare system. Nonetheless, given the characteristics of the population, consistent with other cohorts internationally, we feel the detailed information provided is of value outside of Ireland and will help inform unit development internationally. Secondly the analysis of medication use in the HFrEF cohort does demonstrate modest use of aldosterone antagonists during the first three months post-discharge. This reflects the fact that many of these patients would have gone through this three-month period before use of these agents would have become standard.

In summary, the workload associated with a disease management program following patient discharge from hospital is intense, and requires a flexibility of approach to help avoid rehospitalization. There are greater short-term (3 month) costs associated with HFrEF versus HFpEF as part of a HF-DMP following an index admission. However, longer term (3-12 month) costs of HFpEF are greater because of higher non-cardiovascular re-hospitalisations. As HFpEF becomes the dominant form of community HF, more work is required in HF-DMPs to address prevention of non-cardiovascular rehospitalisations and to integrate hospital based HF-DMPs into primary care healthcare structures.

\section{Acknowledgements:}

The authors wish to acknowledge the contributions of all the staff, both past and present, of the Heart Failure Unit, St. Vincent's University Hospital. Additionally, the authors wish to acknowledge grant support from the Health Service Executive of Ireland. 
Table 1: Population Demographics

\begin{tabular}{|c|c|c|c|}
\hline & All $(n=1292)$ & $\begin{array}{l}\mathrm{HFrEF} \\
(\mathrm{n}=879)\end{array}$ & HFpEF $(n=413)$ \\
\hline Age, median[IQR] years & $\begin{array}{l}74.5 \\
{[65.8: 81.2]}\end{array}$ & $\begin{array}{l}72 \\
{[62.9: 79.6]}\end{array}$ & $\begin{array}{l}78.9 \\
{[71.6: 84.4]^{\star \star \star}}\end{array}$ \\
\hline Male, n (\%) & 759 (58.7\%) & $574(65.3 \%)$ & $185(44.8 \%)^{\star \star \star}$ \\
\hline BMI, median[IQR] kg/m² & $\begin{array}{l}27.2 \\
{[23.8: 31.1]}\end{array}$ & $\begin{array}{l}26.5 \\
{[23.4: 30.6]}\end{array}$ & $28[25.2: 31.9]^{\star \star}$ \\
\hline SBP, median [IQR] mmHg & $\begin{array}{l}122 \\
{[110: 138]}\end{array}$ & $\begin{array}{l}120 \\
{[106: 134]}\end{array}$ & $\begin{array}{l}130 \\
{[116: 144]^{\star \star \star}}\end{array}$ \\
\hline Charlson score, mean (sd) & $6[5: 7]$ & $6[5: 7]$ & $7[6: 8]^{\star \star \star}$ \\
\hline \multicolumn{4}{|l|}{ Heart Failure Etiology, n (\%) } \\
\hline Ischemic & $571(46.9 \%)$ & $418(50.2 \%)$ & $153(39.7 \%)^{\star \star}$ \\
\hline Hypertension & $591(45.7 \%)$ & $351(39.9 \%)$ & $240(58.1 \%)^{\star \star \star}$ \\
\hline Valvular & $129(10.6 \%)$ & $68(8.2 \%)$ & $61(15.8 \%)^{\star \star \star}$ \\
\hline Idiopathic & $141(11.6 \%)$ & $114(13.7 \%)$ & $27(7 \%)^{\star \star}$ \\
\hline Alcohol/Drugs & $85(7.0 \%)$ & $80(9.6 \%)$ & $5(1.3 \%)^{\star \star \star}$ \\
\hline \multicolumn{4}{|l|}{ Lab results, median [IQR] } \\
\hline Admission BNP, pg/mL & $\begin{array}{l}790 \\
{[427: 1400]}\end{array}$ & $\begin{array}{l}894 \\
{[485: 1502]}\end{array}$ & $\begin{array}{l}602 \\
{[398: 1185]^{\star \star \star}}\end{array}$ \\
\hline Discharge BNP, pg/mL & $\begin{array}{l}443 \\
{[224: 818]}\end{array}$ & $\begin{array}{l}502 \\
{[263: 906]}\end{array}$ & $\begin{array}{l}349 \\
{[185: 617]^{\star \star \star}}\end{array}$ \\
\hline Baseline Hemoglobin, g/dL & $\begin{array}{l}12.7 \\
{[11.3: 14.2]}\end{array}$ & $\begin{array}{l}12.9 \\
{[11.6: 14.4]}\end{array}$ & $\begin{array}{l}12.1 \\
{[10.7: 13.4]^{\star \star \star}}\end{array}$ \\
\hline Baseline Creatinine, $\mu \mathrm{mol} / \mathrm{L}$ & $\begin{array}{l}104 \\
{[85.5: 132]}\end{array}$ & 103 [86:129] & 106 [84:142] \\
\hline Baseline Urea, mmol/L & $\begin{array}{l}8.5 \\
{[6.4: 11.8]}\end{array}$ & $\begin{array}{l}8.2 \\
{[6.3: 11.2]}\end{array}$ & $9.2[6.7: 13.3]^{\star \star}$ \\
\hline \multicolumn{4}{|l|}{ ECG, n (\%) } \\
\hline LBBB & $300(23.2 \%)$ & $253(28.8 \%)$ & $47(11.4 \%)^{\star \star \star}$ \\
\hline A. Fib. & $556(43 \%)$ & 349 (39.7\%) & $207(50.1 \%)^{\star \star}$ \\
\hline $\begin{array}{l}\text { Length of Stay (Index admission), median [IQR] } \\
\text { days }\end{array}$ & 9 [6:15] & 10 [6:15] & $8[5: 14]^{\star \star}$ \\
\hline
\end{tabular}


${ }^{*} \mathrm{p}<.05,{ }^{* *} \mathrm{p}<.01,{ }^{* * *} \mathrm{p}<.001$

NOTE: Percentages are calculated using only those patients with data available for that variable. IQR - Interquartile range, BMI- Body mass index, SBP- Systolic Blood Pressure, sd- standard deviation, BNP - B-Type naturetic peptide, ECG- electrocardiogram, LBBB- Left Bundle Branch Block, A.Fib- Atrial Fibrillation.

Table 2:

Event Count and Event rate per Patient /Year

\begin{tabular}{|l|l|l|}
\hline & HFrEF (n=879) & HFpEF (n=413) \\
\hline All Admissions, (Event rate per & $754,(0.858)$ & $409,(0.99)$ \\
\hline ADHF & $152,(0.173)$ & $91,(0.22)$ \\
\hline Death & $117,(0.133)$ & $51,(0.123)$ \\
\hline Elective CV & $43,(0.049)$ & $9(0.022)$ \\
\hline Elective non-CV & $58(0.066)$ & $21(0.051)$ \\
\hline Emergency non ADHF CV & $94,(0.107)$ & $38,(0.092)$ \\
\hline Emergency non-CV & $276,(0.314)$ & $191,(0.462)$ \\
\hline Other & $14(0.016)$ & $8,(0.020)$ \\
\hline Emergency CV and ADHF & $246,(0.280)$ & $129,(0.314)$ \\
\hline
\end{tabular}


Table 3: Average cost per-patient in first year.

\begin{tabular}{|c|c|c|}
\hline $\begin{array}{l}\text { Average cost per-patient Euros* }(95 \% \\
\mathrm{Cl})\end{array}$ & HFrEF $(n=879)$ & HFpEF $(n=413)$ \\
\hline Index Admission (LOS based) & $7660(7047,8354)$ & $6302(5673,7004)$ \\
\hline Readmission Costs & $4287(3574,5042)$ & $5396(4390,6494)$ \\
\hline$A D H F$ & $1150(835,1526)$ & $1150(773,1571)$ \\
\hline Death & $116(63,186)$ & $73(32,133)$ \\
\hline Elective CV & $134(51,265)$ & $32(5,77)$ \\
\hline Elective non-CV & $216(115,351)$ & $79(33,135)$ \\
\hline Emergency CV & $584(396,812)$ & $655(318,1073)$ \\
\hline Emergency non-CV & $2039(1528,2627)$ & $3386(2631,4213)$ \\
\hline Other & $47(16,89)$ & $21(3,48)$ \\
\hline DMP Clinical Workload $(0-3 m)$ & $791(764,819)$ & $693(660,728)$ \\
\hline Unscheduled & $83(72,94)$ & $80(67,94)$ \\
\hline Scheduled (including Titration) & $617(594,640)$ & $528(501,556)$ \\
\hline Telephone (outbound)** & $77(75,79)$ & $71(68,74)$ \\
\hline Telephone (inbound) ${ }^{\star \star}$ & $15(14,16)$ & $14(13,16)$ \\
\hline DMP Clinical Workload (3-12m) & $751(701,802)$ & $593(533,655)$ \\
\hline Unscheduled & $73(62,86)$ & $78(62,96)$ \\
\hline Scheduled (including Titration) & $643(600,688)$ & $485(435,537)$ \\
\hline Telephone (outbound)** & $20(17,23)$ & $18(15,22)$ \\
\hline Telephone (inbound) ${ }^{\star \star}$ & $14(12,16)$ & $11(8,13)$ \\
\hline Medications & $596(579,613)$ & $527(505,550)$ \\
\hline GP visits & $594(582,608)$ & $569(551,587)$ \\
\hline All Costs & $13011(12011,14078)$ & $12206(11009,13518)$ \\
\hline
\end{tabular}




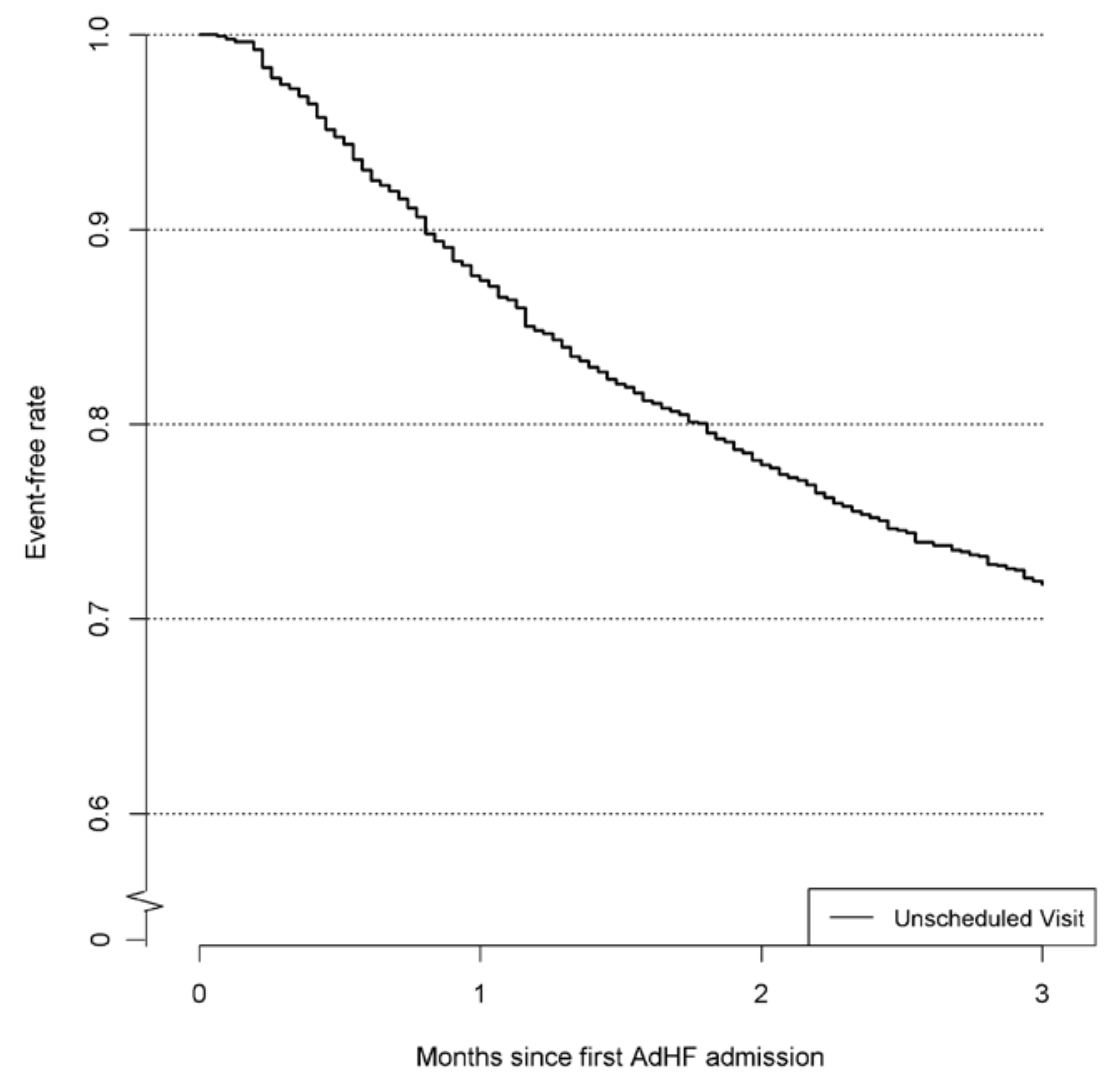

Figure 1. Kaplan-Meier graph demonstrating time to first Unscheduled Clinic Visit post discharge

Cost analysis of a hospital based heart failure disease management programme.

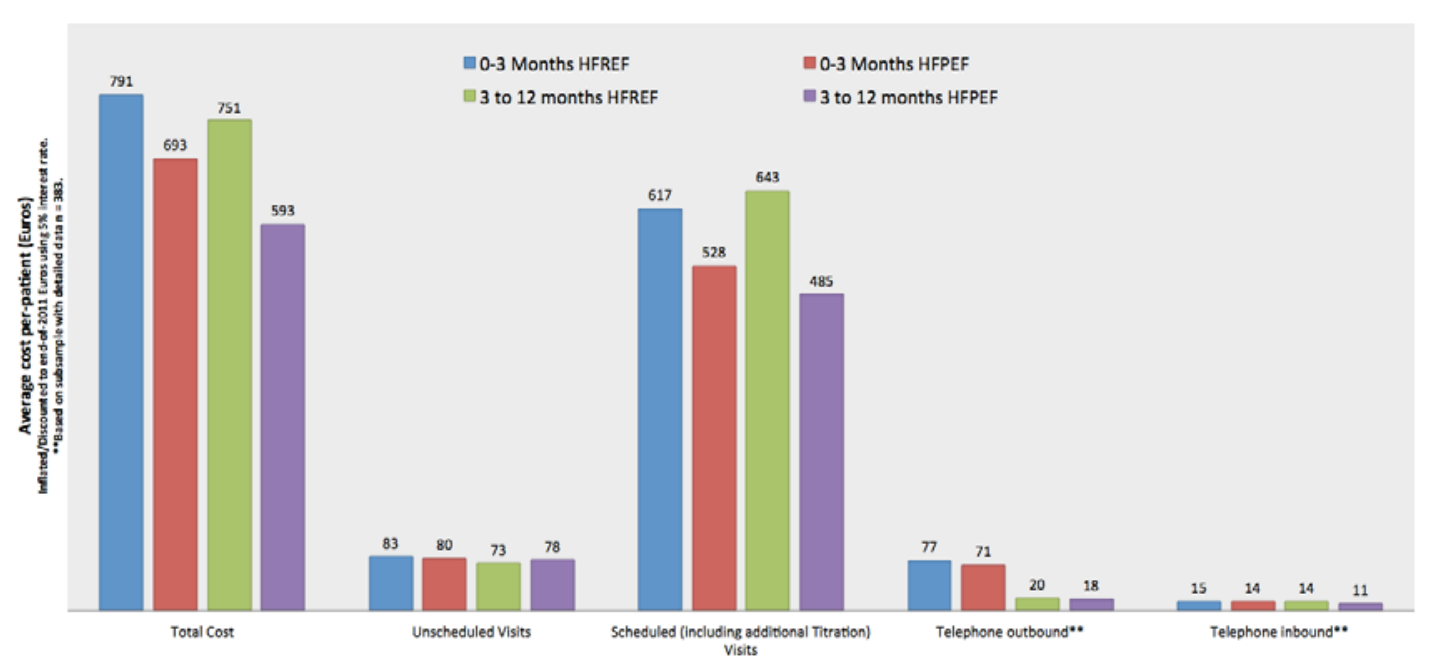

Figure 2 
Appendix: Structure of SVUH DMP

\section{St Vincent's Healthcare Group Heart Failure Disease Management Programme}

Patients admitted with a primary diagnosis of HF are assessed by our HF cardiologists and transferred to the cardiology service for further management. Patients are excluded from enrolment to our service only if they or a family member so wish, if suffering from a terminal illness, have dementia to a level where the patient cannot take part in self-care or are resident outside our catchment area. Management includes complete work up of the cause of HF, assessment of the likely precipitant of admission and initiation of appropriate therapy. Once clinically improved, comprehensive one-on-one education with the patient is initiated regarding standard self-care issues. Contact is also made with the next of kin for education on what to expect on discharge and how to recognise features of decompensation. Discharge planning is initiated when the patient is deemed euvolaemic, or as near to this state as can be effectively achieved.

The outpatient programme is run from a chronic ambulatory care facility, which provides scheduled and unscheduled clinic access Monday to Friday 9am $-5 \mathrm{pm}$ and unscheduled access at weekends through the on-call cardiology service in the hospital. All patients have three scheduled assessment visits during the 3-month period post discharge; within two weeks of discharge (exact timing determined by clinical stability on discharge), and again at 6 weeks and 12 weeks. Nurse-initiated phone consultations (outbound calls) are made to the patients within 48-hours of hospital discharge and then weekly for 12 weeks except on clinic visit weeks. The purpose of these calls is to assess well-being and address any patient concerns. Additionally, these outbound calls provide an opportunity for our HF nurse specialists to engage with the patient on matters such as medication adherence, self-care, body weight measurement, exercise and adherence to any dietary restrictions.

Patients, their carers or general practitioners can contact the unit outside of these scheduled contacts for assistance in management of features suggestive of emerging clinical 
deterioration. These calls are triaged by a nurse specialist and decision made to manage remotely or review the patient at the clinic that day if indicated (unscheduled clinic visit). At weekends and public holidays, patients and carers have a number to call to access the on-call cardiology medical staff in our department who provided the same service as outlined above, including clinical review if needed at the weekend.

At completion of the 12-week programme, patients are reassessed and categorised as either high or low risk for future HF events. High-risk status is a decision made by the consultant in charge and influenced by event history since discharge and B-type natriuretic peptide (BNP) level at three months (BNP $>300 \mathrm{pg} / \mathrm{ml}$ considered high risk). Low risk patients have care transferred back to the primary care physician. High-risk patients have continued close follow up in the DMP. All patients irrespective of risk status are seen at annual intervals for clinical and self care reassessment. 
1 Rosamond W, Flegal K, Furie K, Go A, et al; American Heart Association Statistics Committee and Stroke Statistics Subcommittee. Heart disease and stroke statistics-2008 update: a report from the American Heart Association Statistics Committee and Stroke Statistics Subcommittee. Circulation 2008;117:e25-146.

2Go AS, Mozaffarian D, Roger VL, et al. American Heart Association Statistics Committee and Stroke Statistics Subcommittee. Heart disease and stroke statistics--2013 update: a report from the American Heart Association. Circulation. 2013;127:e6-e245.

3 Krumholz HM, Merrill AR, Schone EM, et al. Patterns of hospital performance in acute myocardial infarction and heart failure 30-day mortality and readmission. Circ Cardiovasc Qual Outcomes. 2009;2:407-13.

4 Maggioni AP, Dahlström U, Filippatos G, et al. Heart Failure Association of the European Society of Cardiology (HFA). Heart Failure Association of the European Society of Cardiology (HFA). EURObservational Research Programme: regional differences and 1-year follow-up results of the Heart Failure Pilot Survey (ESC-HF Pilot). Eur J Heart Fail. 2013; 15:808-17.

5 Au A, McAlister F, Bakal J, Ezekowitz J, Kaul P, van Walraven C. Predicting the risk of unplanned readmission or death within 30 days of discharge after a heart failure hospitalization. Am Heart J. 2012;164:365-372.

6 de la Porte P, Lok D, van Veldhuisen D, et al. Added value of a physician-and-nursedirected heart failure clinic: results from the Deventer-Alkmaar heart failure study. Heart. 2007;93:819-825.

7 Holland R, Battersby J, Harvey I, Lenaghan E, Smith J, Hay L. Systematic review of multidisciplinary interventions in heart failure. Heart. 2005;91:899-906.

8 McAlister F, Bakal J, Kaul P, et al. Changes in Heart Failure Outcomes After a ProvinceWide Change in Health Service Provision A Natural Experiment in Alberta, Canada. Circ Heart Fail. 2012;6:76-82.

9 Takeda A, Taylor SJ, Taylor RS, Khan F, Krum H, Underwood M. Clinical service organisation for heart failure. Cochrane Database Syst Rev. 2012;9:CD002752.

10McAlister F, Stewart S, Ferrua S, McMurray J. Multidisciplinary strategies for the management of heart failure patients at high risk for admission. A systematic review of randomized trials. J Am Coll Card. 2004;44:810-819.

11 Wijeysundera H, Trubiani G, Wang X,et al. A Population-Based Study to Evaluate the Effectiveness of Multidisciplinary Heart Failure Clinics and Identify Important Service Components. Circ Heart Fail. 2013;6(1):68-75.

12 Ponikowski P, Voors A, Anker S, et al. 2016 ESC Guidelines for the diagnosis and treatment of acute and chronic heart failure. European Journal of Heart Failure.

2016;18(8):891-975.

13 Coats, A., \& Shewan, L. The Management of Heart Failure with Preserved Ejection

Fraction (HFpEF). International Cardiovascular Forum Journal. 2014;1:108-112.

14 Blue L, Lang E, McMurray J, et al. Randomised controlled trial of specialist nurse intervention in heart failure. BMJ. 2001;323:715-718.

15 Tsuyuki R, Fradette M, Johnson J, et al. A multicenter disease management program for hospitalized patients with heart failure. J Card Fail. 2004;10:473-480.

16 Angermann C, Stork S, Gelbrich G, et al. Mode of Action and Effects of Standardized

Collaborative Disease Management on Mortality and Morbidity in Patients With Systolic

Heart Failure: The Interdisciplinary Network for Heart Failure (INH) Study. Circ Heart Fail 2011;5:25-35.

17 National Casemix Programme. Ready Reckoner of Acute Hospital inpatient and daycase activity and costs (summarised by DRG) relating to 2010 costs and activity. Ireland: Health Service Executive; 2012. 
18 de la Porte P, Lok D, van Veldhuisen D, et al. Added value of a physician-and-nursedirected heart failure clinic: results from the Deventer-Alkmaar heart failure study. Heart. 2007;93:819-825.

19 Holland R, Battersby J, Harvey I, Lenaghan E, Smith J, Hay L. Systematic review of multidisciplinary interventions in heart failure. Heart. 2005;91:899-906.

20 McAlister F, Bakal J, Kaul P, et al. Changes in Heart Failure Outcomes After a ProvinceWide Change in Health Service Provision A Natural Experiment in Alberta, Canada. Circ Heart Fail. 2012;6:76-82.

21 Wijeysundera H, Trubiani G, Wang X, et al. A Population-Based Study to Evaluate the Effectiveness of Multidisciplinary Heart Failure Clinics and Identify Important Service Components. Circ Heart Fail. 2013;6(1):68-75.

22 van Riet E, Hoes A, Wagenaar K, Limburg A, Landman M, Rutten F. Epidemiology of heart failure: the prevalence of heart failure and ventricular dysfunction in older adults over time. A systematic review. European Journal of Heart Failure. 2016;18(3):242-252.

23 Owan T, Hodge D, Herges R, Jacobsen S, Roger V, Redfield M. Trends in Prevalence and Outcome of Heart Failure with Preserved Ejection Fraction. N Engl J Med. 2006;355:251259.

24 Ryder M, Murphy N, McCaffrey D, O'Loughlin C, Ledwidge M, McDonald K. Outpatient intravenous diuretic therapy; potential for marked reduction in hospitalisations for acute decompensated heart failure. Eur J Heart Fail. 2008;10:267-272.

25 Shah SJ, Gheorghiade M. Heart failure with preserved ejection fraction: treat now by treating comorbidities. JAMA 2008;300;431-3 